\title{
Erratum: Effects of rf breakdown on the beam in the Compact Linear Collider prototype accelerator structure [Phys. Rev. ST Accel. Beams 16, 081004 (2013)]
}

\author{
A. Palaia, ${ }^{*}$ M. Jacewicz, R. Ruber, and V. Ziemann \\ W. Farabolini \\ (Received 15 November 2013; published 6 December 2013)
}

DOI: $10.1103 /$ PhysRevSTAB.16.129901

PACS numbers: 29.20.Ej, 52.80.Pi, 29.27.-a, 99.10.Cd

We identified a misprint in our paper. In the list of parameters of the CLIC prototype accelerator structure given in Table II, the value of the input power (loaded) should read 64 MW for a CLIC main linac nominal pulse consisting of 312 bunches, each one carrying a charge of $0.6 \mathrm{nC}$ [1]. This corresponds to an accelerating gradient of $100 \mathrm{MV} / \mathrm{m}$ averaged over all cells, as in the unloaded case given in the same Table.

The results and conclusions of the article are not affected.

[1] R. Zennaro et al., in Proceedings of the 24th International Linear Accelerator Conference LINAC08, Victoria, British Columbia, Canada (TRIUMF, Vancouver, 2008), pp. 533-535.

\footnotetext{
*Corresponding author. andrea.palaia@physics.uu.se

Published by the American Physical Society under the terms of the Creative Commons Attribution 3.0 License. Further distribution of this work must maintain attribution to the author(s) and the published article's title, journal citation, and DOI.
} 